\title{
Serial Reduction of an Extremely Large Gastroschisis using Vacuum-Assisted Closure
}

\author{
Marilyn W. Butler ${ }^{1} \quad$ Julie Fuchs $^{2}$ Matias Bruzoni ${ }^{2}$ \\ ${ }^{1}$ Division of Pediatric Surgery, Department of Surgery, Oregon Health \\ and Science University, Portland, Oregon, United States \\ 2 Division of Pediatric Surgery, Department of Surgery, Stanford \\ University, Stanford, California, United States
}

\begin{abstract}
Address for correspondence Marilyn W. Butler, MD, MPH, Division of Pediatric Surgery, Department of Surgery, Oregon Health and Science University, 501 N Graham Street, Suite 300, Portland, OR 97227, United States (e-mail: mwbutler@gmail.com).
\end{abstract}

Eur J Pediatr Surg Rep 2018;6:e97-e99.
Abstract
Keywords
- gastroschisis
- omphalocele
- vacuum-assisted closure
- VAC
- negative-pressure wound therapy

We herein describe a case of serial reduction of an extremely large and complex gastroschisis using vacuum-assisted closure (VAC) therapy in a boy born at $35^{5 / 7}$ weeks' gestation. A spring-loaded silicone silo was placed at birth. By day of life (DOL) 22, minimal visceral contents had been reduced, and the silo was difficult to maintain due to the size of the fascial defect and loss of abdominal domain. A bespoke VAC dressing was constructed, and biweekly dressing changes allowed gradual reduction of the gastroschisis until the viscera were consolidated. By DOL 50, the viscera were completely reduced, and VAC therapy was discontinued. Feeds were commenced on DOL 57 and increased to goal by DOL 86 . The baby was discharged home on DOL 115. We conclude that VAC dressings can be used to aid gradual reduction of an extremely large gastroschisis, particularly in medical fragile infants.

\section{New Insights and the Importance for the Pediatric Surgeon}

When silo closure fails, an extremely large gastroschisis can be gradually reduced with VAC dressings, thereby avoiding the use of synthetic or biological mesh.

\section{Introduction}

While mortality of gastroschisis in some low- and middleincome countries remains as high as $100 \%$, in developed countries, gastroschisis mortality is an extremely rare occurrence given access to skilled neonatal and surgical care, including ventilator support and total parenteral nutrition. However, complex gastroschisis, whether it is defined by gastrointestinal issues or abdominal wall factors, behaves as a disease process with much worse prognosis. ${ }^{1}$

Despite improvements in survival, gastroschisis closure remains challenging, particularly when the fascial defect is large, eviscerated contents are substantial, medical status is precarious, or abdominal domain is lost.

Negative-pressure wound therapy (NPWT), including vacuum-assisted closure (VAC), has been used in children since the 1990s for other challenging wounds to promote the formation of granulation tissue, reduce edema, remove infection, and control fluid losses. ${ }^{2,3}$ Previous series have described the application of NPWT for gastroschisis following silo placement after the eviscerated bowel is consolidated. $^{2,4,5}$ We herein report the first case where VAC therapy was used to reduce a significantly matted mass of eviscerated bowel in an infant with gastroschisis.

\section{Case Report}

A boy with gastroschisis was born at $35^{5 / 7}$ weeks' gestation weighing $2.120 \mathrm{~kg}$, to a G2P1 mother through vaginal delivery. Through a defect measuring approximately $4 \mathrm{~cm}$ in diameter, a substantial portion of matted abdominal contents was eviscerated, including the stomach, small intestines, and colon. A received

July 4, 2018

accepted after revision

October 11, 2018

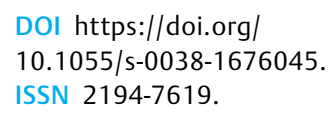

DOI https://doi.org/ 10.1055/s-0038-1676045. ISSN 2194-7619.

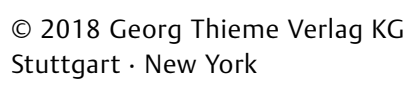

License terms

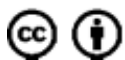




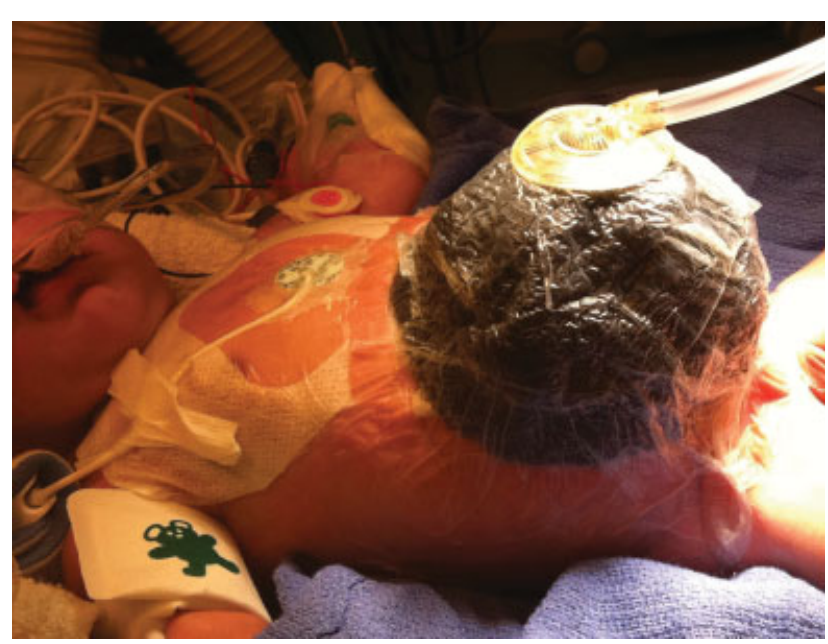

Fig. 1 Initial vacuum-assisted closure dressing on day of life 22 .

spring-loaded 5-cm Silicone Silo Bag was placed at birth (Bentec Medical, Woodland, California, United States) and was eventually upsized to a 7.5-cm Silicone Silo Bag. By day of life (DOL) 22, minimal visceral contents had been reduced, and the silo was difficult to maintain due to the large size of the fascial defect and loss of abdominal domain. A bespoke VAC dressing was constructed as follows: Whitefoam and GranuFoam (KCI Medical, San Antonio, Texas, United States) dressings were cut to half their thickness, fashioned in the shape of a cup by sewing strips together, and placed over the eviscerated bowel. Strips of adhesive drapes were used to secure the dressing, circumferentially wrapping the infant. After puncturing the drape, a SensaT.R.A.C. Pad (KCI Medical) was placed over the dressing, connected to a VAC therapy unit, and placed to negative pressure that ranged between 25 and $75 \mathrm{~mm} \mathrm{Hg}$ (-Fig. 1).

Endotracheal intubation was necessary for biweekly dressing changes until the viscera were consolidated (-Fig. 2). Then Mepitel (Mölnlycke Health Care, Gothenburg, Sweden) was placed over the viscera prior to Whitefoam and GranuFoam dressings ( - Fig. 3). By DOL 50, the abdominal contents

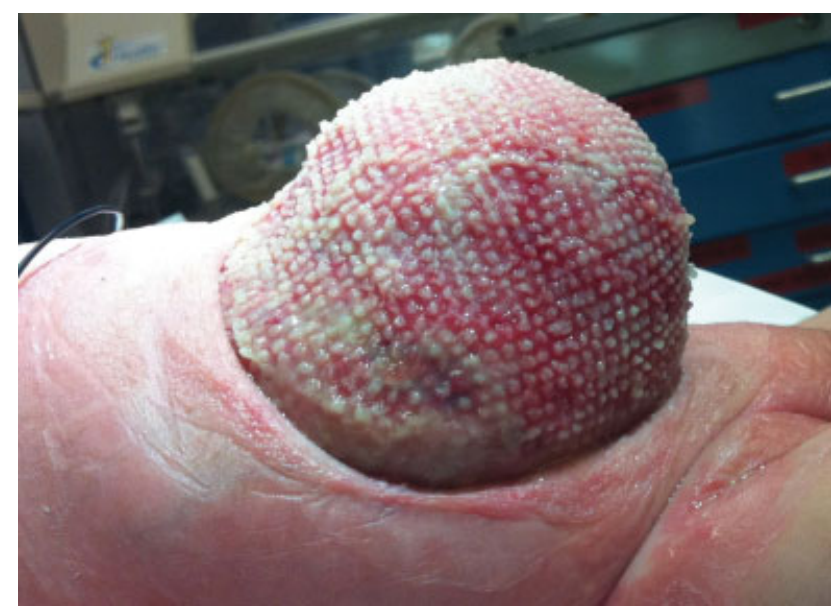

Fig. 2 Gastroschisis on day of life 29, 7 days after vacuum-assisted closure dressing was placed, showing consolidation of herniated abdominal contents.

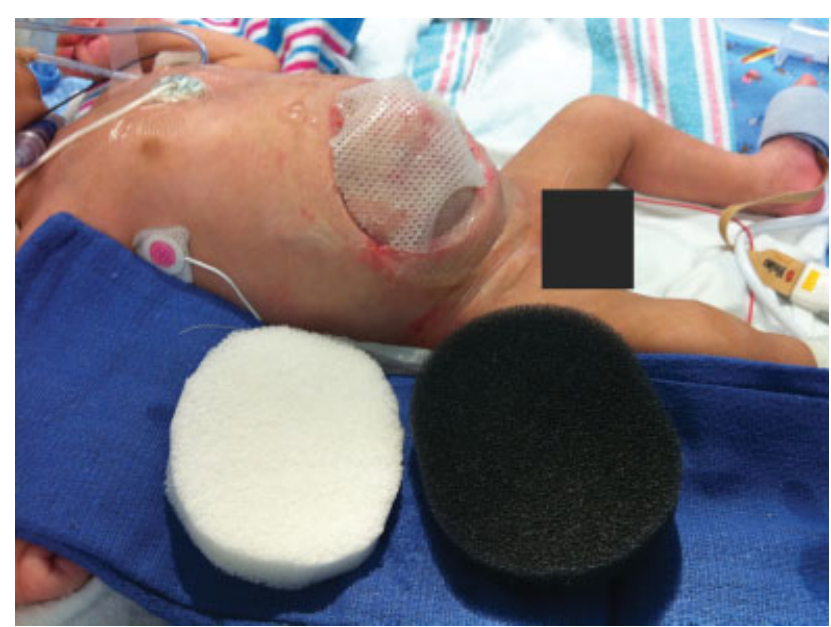

Fig. 3 Gastroschisis on day of life 39, 17 days after vacuum-assisted closure dressing was placed, showing dressing materials and nearly complete reduction of herniated abdominal contents.

were completely reduced, and VAC therapy was discontinued. Mepitel was placed until the wound was closed (-Fig. 4).

Feeds were commenced on DOL 57 and increased to goal by DOL 86 . The baby was discharged home on DOL 115 . While initially anemic with cholestasis, by follow-up at 13 months, both had resolved, and his weight was at the 50th percentile for his age. At that point, he was discharged from the clinic and lost to further follow-up. At follow-up clinic visits, the skin had completely epithelialized. An incisional hernia was not noted, although it is presumed that one was present.

\section{Discussion}

Gastroschisis closure has challenged pediatric surgeons for decades. Standard of care for many years entailed immediate primary closure at birth, which resulted in respiratory compromise, abdominal compartment syndrome, bowel ischemia, decreased lower extremity perfusion, anuria, and need for vigorous fluid resuscitation to maintain blood pressure. ${ }^{6}$ Occasionally, in challenging cases, silicone sheeting or other plastic

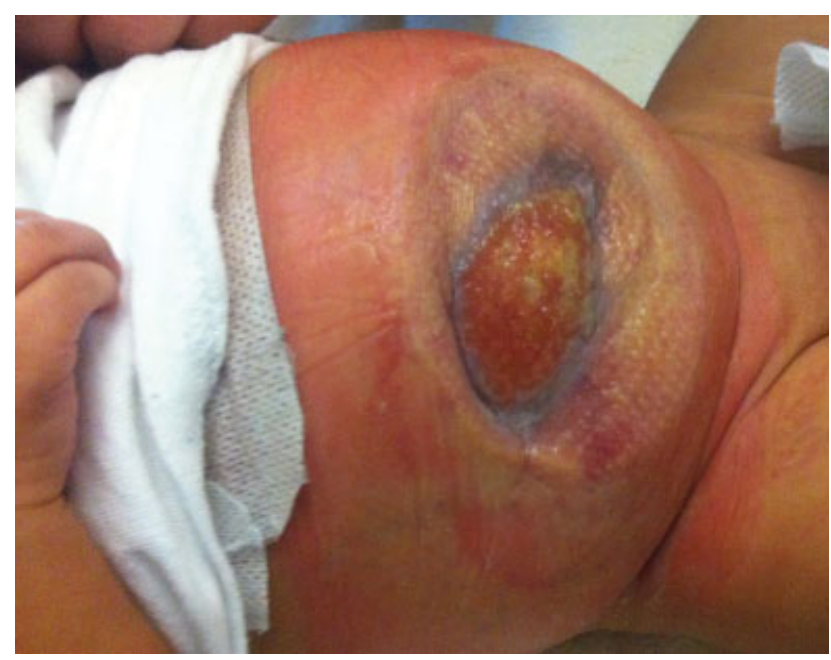

Fig. 4 Gastroschisis on day of life 78, showing wound contraction. 
materials such as intravenous bags were sewn to the edges of the fascia or the skin to create temporary silos until the viscera could be gradually reduced. ${ }^{7-10}$ Some used pneumatic pressure or wringer clamps to reduce the viscera within the silos. ${ }^{11,12}$ With time, however, the fascial defect typically grew larger, and sutures caused the fascia to lose its integrity, making subsequent closure more difficult. In 1995, the introduction of spring-loaded Silicone Silo Bags that could be easily placed at the bedside made delayed closure more convenient, and primary reduction was reserved for newborns whose abdominal contents could be reduced without significant physiological consequences. $^{13-15}$ In some resource-poor countries, locally sourced female condoms have been used when spring-loaded silicone silos are not available. ${ }^{16}$

Despite these advances, in patients with large fascial defects and loss of abdominal domain, use of spring-loaded silos has been unsuccessful in reducing the gastroschisis. At various times, surgeons have used muscle or skin flaps, ${ }^{17,18}$ skin grafts, ${ }^{19}$ synthetic mesh, ${ }^{20}$ biological mesh, ${ }^{21}$ amniotic grafts, ${ }^{22}$ and pericardial patches ${ }^{23}$ to achieve visceral coverage and reduce fluid and heat losses. Skin does not readily cover many of these materials, however, and often mesh needs to be removed ${ }^{7,17,20,24}$ or leads to recurrence. ${ }^{21}$

More recently, sutureless closure of gastroschisis has incorporated the umbilical cord as a biological dressing for primary repair or delayed closure after silo placement. ${ }^{25,26}$ After the cord sloughs, VAC dressings are often used to cover the exposed viscera until the wound is epithelialized. ${ }^{2,4,5}$ Until the successful closure in our patient, however, there have been no reports of the use of VAC dressings for primary coverage in gastroschisis that has not yet been reduced. Although our patient did need intubation for the first few dressing changes, once the bowel was consolidated, the VAC dressing could be applied without sedation. Feeds were commenced once the abdomen was closed, and cholestatic liver changes resolved after 13 months.

We do note that our patient's initial management with the silo bag might have made eventual reduction more difficult. Although we generally use the smallest silo bag possible in order not to enlarge the fascial defect, our patient's defect was initially relatively large, and therefore we had no choice than to use a 5$\mathrm{cm}$ silo bag. Upsizing the silo bag made the fascial defect even larger, and in retrospect, were we to encounter the same problem again, we would opt to commence VAC dressings sooner.

We conclude that VAC dressings can be used to aid gradual reduction of extremely large gastroschisis anomalies, particularly in medically fragile infants, without the need for synthetic or biological mesh.

\section{Conflict of Interest}

None.

\section{References}

1 Laje P, Fraga MV, Peranteau WH, et al. Complex gastroschisis: clinical spectrum and neonatal outcomes at a referral center. J Pediatr Surg 2018;53(10):1904-1907

2 Stoffan AP, Ricca R, Lien C, Quigley S, Linden BC. Use of negative pressure wound therapy for abdominal wounds in neonates and infants. J Pediatr Surg 2012;47(08):1555-1559
3 Lopez G, Clifton-Koeppel R, Emil S. Vacuum-assisted closure for complicated neonatal abdominal wounds. J Pediatr Surg 2008;43 (12):2202-2207

4 McBride CA, Stockton K, Storey K, Kimble RM. Negative pressure wound therapy facilitates closure of large congenital abdominal wall defects. Pediatr Surg Int 2014;30(11):1163-1168

5 Choi WW, McBride CA, Kimble RM. Negative pressure wound therapy in the management of neonates with complex gastroschisis. Pediatr Surg Int 2011;27(08):907-911

6 Yaster M, Buck JR, Dudgeon DL, et al. Hemodynamic effects of primary closure of omphalocele/gastroschisis in human newborns. Anesthesiology 1988;69(01):84-88

7 Cordero L, Touloukian RJ, Pickett LK. Staged repair of gastroschisis with Silastic Sheeting. Surgery 1969;65(04):676-682

8 Schuster SR. A new method for the staged repair of large omphaloceles. Surg Gynecol Obstet 1967;125(04):837-850

9 Gilbert MG, Mencia LF, Puranik SR, Litt RE, Altman DH. Management of gastroschisis and short bowel: report of 17 cases. J Pediatr Surg 1972;7(05):598-607

10 Kidd JN Jr, Jackson RJ, Smith SD, Wagner CW. Evolution of staged versus primary closure of gastroschisis. Ann Surg 2003;237(06): 759-764, discussion 764-765

11 Sawin R, Glick P, Schaller R, Hatch E, Hall D, Hicks L. Gastroschisis wringer clamp: a safe, simplified method for delayed primary closure. J Pediatr Surg 1992;27(10):1346-1348

12 Othersen HB Jr, Smith CD. Pneumatic reduction bag for treatment of gastroschisis and omphalocele. A 10-year experience. Ann Surg 1986;203(05):512-516

13 Bianchi A, Dickson AP. Elective delayed reduction and no anesthesia: 'minimal intervention management' for gastrochisis. J Pediatr Surg 1998;33(09):1338-1340

14 Lansdale N, Hill R, Gull-Zamir S, et al. Staged reduction of gastroschisis using preformed silos: practicalities and problems. J Pediatr Surg 2009;44(11):2126-2129

15 Fischer JD, Chun K, Moores DC, Andrews HG. Gastroschisis: a simple technique for staged silo closure. J Pediatr Surg 1995;30 (08):1169-1171

16 Bustorff-Silva JM, Schmidt AF, Gonçalves A, Marba S, Sbragia L. The female condom as a temporary silo: a simple and inexpensive tool in the initial management of the newborn with gastroschisis. J Matern Fetal Neonatal Med 2008;21(09):648-651

17 Fonkalsrud EW, Smith MD, Shaw KS, Borick JM, Shaw A. Selective management of gastroschisis according to the degree of visceroabdominal disproportion. Ann Surg 1993;218(06):742-747

18 Aoyama K. A new operation for repair of large ventral hernias following giant omphalocele and gastroschisis. J Pediatr Surg 1979;14(02):172-176

19 Anderl H, Menardi G, Hager J. Closure of gastroschisis by mesh skin grafts in problem cases. J Pediatr Surg 1986;21(10): 870-872

20 Stringel G. Large gastroschisis: primary repair with Gore-Tex patch. J Pediatr Surg 1993;28(05):653-655

21 Beres A, Christison-Lagay ER, Romao RL, Langer JC. Evaluation of Surgisis for patch repair of abdominal wall defects in children. J Pediatr Surg 2012;47(05):917-919

22 Gharib M, Ure BM, Klose M. Use of amniotic grafts in the repair of gastroschisis. Pediatr Surg Int 1996;11(2-3):96-99

23 van Tuil C, Saxena AK, Willital GH. Experience with management of anterior abdominal wall defects using bovine pericard. Hernia 2006;10(01):41-47

24 T Adikibi B, O'Toole S. Reverse tissue expansion in gastroschisis: what to do if the defect is too large to close after silo removal? J Neonatal Surg 2014;3(04):47

25 Zivković SM. Repair of gastroschisis using umbilical cord as a patch. J Pediatr Surg 1991;26(10):1179-1180

26 Sandler A, Lawrence J, Meehan J, Phearman L, Soper R. A "plastic" sutureless abdominal wall closure in gastroschisis. J Pediatr Surg 2004;39(05):738-741 